\title{
Comparative Study to Assess the Knowledge on Worm Infestation among Urban and Rural Mothers of School Going Children (3-12 Yrs) at Karaikal District
}

\author{
Kalaivani E. ${ }^{1}$, G. Ambujam² \\ ${ }^{1}$ Assistant Professor, Vinayaka Mission's College of Nursing, Karaikal, Puducherry (UT), ${ }^{2}$ Dean \& Professor of \\ Surgery, Research Guide, Vinayaka Mission's Medical College \& Hospital, Karaikal, Puducherry (UT), Vinayaka \\ Mission's Research Foundation (Deemed to be University), Salem
}

\begin{abstract}
Background: Helminthes infections are more prevalent among school children aged 5-14 years. Hookworm burden is the major etiology for iron deficiency anemia in young children. One of the major health concerns especially among children is anemia and malnutrition. This risk has further complicated by lack of awareness on prevention of worm infestation among children and parents, care givers especially mothers. Increasing children's and their Parents awareness of the problem can help to fight the disease.
\end{abstract}

Objectives: To assess the knowledge on worm infestation among urban and rural mothers of School going children.

Materials and Method: Non-experimental Comparative study was conducted to assess the knowledge among mothers in urban and rural area at Karaikal. Sample size comprised of 150 mothers of school going children were selected through non-probability or non-randomized convenience sampling. Out of 150 mothers 75 mothers from urban area and 75 mothers from rural area. The data was collected by using pretested structured knowledge questionnaire. Data was analyzed by both descriptive and inferential statistics.

Results: This study revealed that in urban area the majority of the mothers of school going children $37 \%(28)$ had adequate knowledge, 40\%(30) had moderately adequate knowledge and 23\%(17) had inadequate knowledge regarding worm infestation. Also revealed that in rural area the majority of the mothers of school going children 35\%(26) had inadequate knowledge, 36\%(27) had moderately adequate knowledge and 29\%(22) had adequate knowledge regarding worm infestation. Mean and standard deviation (SD) of the urban and rural area mothers of school going children respectively 16.8 $\pm 4.77,15.01 \pm 5.16$.

Conclusion: The researcher concluded that the need for more research to improve not only the knowledge also attitude and practices among mothers of school age children on worm infestations.

Keywords: Knowledge, worm infestations, Urban, Rural, Mothers of school going children.

\section{Introduction}

Children are nature's gift and the fountain of life.

\section{Corresponding Author:}

\section{Kalaivani E.}

Assistant Professor, Vinayaka Mission's College of

Nursing, Karaikal, Puducherry (UT)

e-mail: kalaivaninew.2010@gmail.com
They are our future and are a supremely important asset of the nation. They have to be protected and look after. By promoting their health, we will be strengthening the development of the family, Country, Nation and World. ${ }^{1}$

Child development and wellbeing is influenced by many factors comprises the socio economic status of the family, educational level of the parents especially the mother, availability of safe drinking water and sanitary facilities and accessibility to health care services. 
One of the silent and prevalent diseases in developing countries especially India is Worm infestation. It is more prevalent among school children. It can cause nutritional impairment and poor development of children. Knowledge of the worm infestation can assist in early detection of the diseases and reduce the incidence of complications. $^{2,3,4}$

In world's population $24 \%$ or more than 1.5 billion people are infected with soil-transmitted helminth infections worldwide. Preschool-age children over 267 million and school-age children over 568 million live in areas where these parasites are intensively transmitted and are in need of interventions. Global wise over 600 million persons are estimated to be infected by S. stercoralis. Eggs that are attached to vegetables are ingested when the vegetables are not carefully cooked, peeled, washed in contaminated water and soil. Hookworm primarily can actively penetrate the skin when walking barefoot on the contaminated soil. Infestations causes' loss of appetite leads to less nutritional intake affects the physical fitness, diarrhea,loss of iron,protein and anemia. Health and hygiene education reduces transmission and re-infection by encouraging healthy behavior and provision of adequate sanitation. Because the main reason for infestations is poor personal and environmental sanitation. In 2018, over 676 million school-aged children were treated with anti helminthic medicines in endemic countries, corresponding to $53 \%$ of all children at risk. ${ }^{5}$

In India, 225 million preschool(3-6yrs) and schoolage (6-12 yrs) children are estimated to be at risk of worm infestations. India accounts for $65 \%$ of soil-transmitted helminth (parasitic worms) cases at South East Asia and $27 \%$ of cases world wide. In recent years, India has implemented national deworming programme, through which almost 250 million children are dewormed in February and August (twice a year). ${ }^{6,7}$

The prevalence of anemia among the entire study population (350 children) and in those infected with worms was $56.6 \%$ and $56.9 \%$ respectively. With polyparasitism there was a relative increase in the frequency of anemia in females than males. ${ }^{8}$

Worm infections and anemia are common in our children. Comprehensive control strategy involving good sanitation, supply of clean water and regular deworming (six month once) are recommended to prevent or reduce the prevalance. ${ }^{6}$ Multiple socio-economical, cultural, physiological and behavioral parameters along with illiteracy and poor sanitation influence intestinal parasitic infection. Awareness on infectious diseases, improving hygiene and application of supportive programs for parents to elevate socioeconomic conditions may reduce the burden of infection.

\section{Materials and Method}

The research approach adopted for the present study was Non Experimental Comparative research approach. Participants were selected by using non-probability or non randamozied convenience sampling technique. The total number of mothers of school going children included was 150(75 from urban and 75 from rural area). The study was conducted at Karaikal, Puducherry (U.T). The tools used for this study were demographic proforma and structured knowledge questionnaire. The structured knowledge questionnaire consisted of 25 items comprised of general aspects of worm infestations, types and mode of transmission, signs, symptoms, diagnosis, Treatment, prevention and complication of worm infestations. The tool was pre-tested by administering it to sixteen mothers of school going children (8 from urban and 8 from rural area). The Participants found that the instructions and the language of the tool were simple,clear and understandable and the time taken to complete the tool was 30 minutes. The reliability of the tool was tested by split half method. A pilot study was conducted to find out the feasibility of the study. Data analysis was done by using both descriptive and inferential statistics

\section{Results}

The study Total participants consisted of $150(75+75)$ mothers of school going children. Among 75 mothers from urban area about 45\%(34)of mothers of school going children belonged to the age group of 31-40 years and majority 40\% (30)of mothers belonged to Hindu. Maximum percentage 55\% (41) of mothers had completed her degree. Most of the mothers $45 \%$ (34) were home maker. Nearly $32 \%$ (24) of the mothers had family monthly income Rs. 10001 to 20,000. Most of the mothers $36 \%$ (27)had information about worm infestations from mass media.

Among 75 mothers from rural area about 45\% (34) of mothers of school going children belonged to the age group of 31-40 years and majority $48 \%$ (36)of mothers belonged to Hindu. Maximum percentage 51\% (38) of 
mothers had completed her degree. Most of the mothers $52 \%$ (39) were home maker. Nearly $39 \%$ (29) of the mothers had family monthly income Rs. 5000 to 10,000 .
Most of the mothers 48\% (36) had information about worm infestations from mass media.

Table 1. Frequency and Percentage distribution regarding knowledge on worm infestations among mothers of school going children from urban and rural area

\begin{tabular}{|l|c|c|c|c|}
\hline \multirow{2}{*}{ Level of Knowledge } & \multicolumn{2}{|c|}{ Mothers from Urban } & \multicolumn{2}{c|}{ Mothers from Rural } \\
\cline { 2 - 5 } & $\mathbf{F}$ & $\mathbf{\%}$ & $\mathbf{F}$ & $\mathbf{\%}$ \\
\hline Inadequate & 17 & $23 \%$ & 26 & $35 \%$ \\
\hline Moderately Adequate & 30 & $40 \%$ & 27 & $36 \%$ \\
\hline Adequate & 28 & $37 \%$ & 22 & $29 \%$ \\
\hline Total & $\mathbf{7 5}$ & $\mathbf{1 0 0 \%}$ & $\mathbf{7 5}$ & $\mathbf{1 0 0 \%}$ \\
\hline
\end{tabular}

Table 2. Mean standard deviation regarding knowledge on worm infestations among mothers of school going children from urban and rural area

\begin{tabular}{|l|c|c|}
\hline Group & Mean & SD \\
\hline Mothers from urban & 16.8 & \pm 4.77 \\
\hline Mothers from rural & 15.01 & \pm 5.16 \\
\hline
\end{tabular}

The chi-square values of demographic variables such as age of the mother, religion, education, occupation, monthly family income and source of information, regarding worm infestation among mothers of school going children from urban area were not significant at $P \leq 0.05$. Thus, it is concluded that there was no association between knowledge score and selected demographic variable

The chi-square values of demographic variables such as age of the mother, occupation, regarding worm infestation among mothers of school going children from rural area were significant at $\mathrm{P} \leq 0.05$. Mean while there was no association with demographic variables such as religion, education, monthly family income and source of information at $\mathrm{P} \leq 0.05$

\section{Discussion}

The high prevalence of parasitic infestation seems directly related to the unhygienic living conditions associated with lack of knowledge about the communicable disease and variety of allied factors, which need to be studied. Socioeconomic status and occupation of parents, the age of children and ethnicity are significantly associated with parasitic infections. ${ }^{9}$ Intervention measures are important to take up sustained health education, provision of safe drinking water and improvement in environmental sanitation. During the school health checkups, periodic screening for intestinal parasites and blood indices can be evaluated. ${ }^{10}$

Present study revealed thatin urban area the majority of the mothers of school going children 37\% (28) had adequate knowledge, $40 \%$ (30) had moderately adequate knowledge and 23\%(17)had inadequate knowledge regarding worm infestation. Also revealed thatin rural area the majority of the mothers of school going children 35\% (26) had inadequate knowledge,36\% (27) had moderately adequate knowledge and 29\%(22)had adequate knowledge regarding worm infestation.

Sadhna Shinde et al conducted a community based, cross-sectional survey of 100 mothers to assessing the knowledge regarding worm infestations in selected slums in pune and revealed that $75 \%$ of the mothers were having average knowledge, $22 \%$ of mothers had poor knowledge \& only $3 \%$ of mothers were having good knowledge regarding worm infestation. ${ }^{11}$

Another one study conducted by Suganya et al to evaluated the Knowledge regarding prevention of worm infestations among mothers of under five children. The result showed that among 60 samples $60(98.4 \%)$ of mothers have inadequate knowledge and $1(1.6 \%)$ of mothers have adequate knowledge regarding prevention of worm infestation. ${ }^{12}$ 
One more study was conducted by Madan Mohan Gupta et al to assess the knowledge regarding worm infestation among mothers of pre-school children. The study result showed that, 48 (48\%) mothers of pre-school children had moderately adequate knowledge, 42 (42\%) had inadequate knowledge and $10(10 \%)$ had adequate knowledge regarding worm infestation. ${ }^{13}$

Descriptive study had been conducted by Sharma Ankit et al on Awareness of Worm Infestation among Mothers and its Prevalence in their Preschool Children. The study results showed that $55 \%$ mothers of preschool children had average knowledge regarding worm infestation followed by $24 \%$ had good and $21 \%$ mothers had poor knowledge. ${ }^{14}$

Another one study conducted by M. Hemamalini et al regarding Knowledge on Worm Infestation among Mothers with Under Five Children 50 mothers, 18 (36\%) mothers have in adequate knowledge; 20 (40\%) mothers have moderately adequate knowledge and 12 (24\%) mothers have adequate knowledge $\mathrm{e}^{15}$

The findings of the present study revealed that mean and standard deviation (SD) of the urban and rural mothers of school going children respectively $16.8 \pm 4.77$, $15.01 \pm 5.16$. Also present study concluded that there was no association between knowledge score and selected demographic variable among urban mothers of school going children. Similar study had been conducted by Rimple Sharma et al and revealed that mean knowledge score of urban mothers was higher (18.86) as compared to rural mothers (16.96) regarding worm infestation in children. It was found that there was no impact of demographic variables on knowledge score of urban mothers. ${ }^{16}$

Jebasubitha conducted study on to assess the effectiveness of structured teaching programme on knowledge regarding prevention of worm infestation among mothers of under five children. The result shows that, there is no significant association between the mean pre-test knowledge scores and the selected demographic variables such as age of the mother, education, type of family, age of the child, family income. ${ }^{17}$

Another one study provides information that most of the caregivers had a good knowledge regarding deworming but failed in practicing necessary measures to control and prevent it. Worm infestation is one of the easily preventable disease. ${ }^{18}$ Health awareness, frequent monitoring, behavior change programme and implementing interventional programs among parents and caregivers particularly among the rural population would be vital. So that the prevalence of the worm infestations can be prevented or minimized ${ }^{19,20,21}$

\section{Conclusion}

The present study concluded that most of the urban and rural mothers had moderately adequate and inadequate knowledge on worm infestations. Hence the knowledge, attitude and practice of the mothers can be enhanced through mass health education program on prevention of worm infestation which in turn promotes the growth and development of the school going children.

\section{Source of Funding: Self}

Conflict of Interest: There is no conflict of interest

Ethical Clearance: Informed consent was taken from the participants prior to the study.

\section{References}

1. Begum SA. A Study on personal hygiene of Government primary school Children in Azadnager and Gouripalya.2017. http://52.172.27.147:8080/ jspui/handle/123456789/3046

2. Rana Saroj, Settipalle Jeen Mexina, Kaur Amiteshwar. International Journal of Advance Research and Development. 2018. Volume 3, Issue 3. Available online at: www.ijarnd.com

3. Mamta Rajput Nebhinani. Research \& Reviews: Journal of Nursing \& Health Sciences RRJNHS| Volume 1 | Issue 3 | May-June, 2015

4. Pooja Gauro .International Journal of Health Sciences \& Research (www.ijhsr.org) 123 Vol.8; Issue: 4; April 2018

5. Soil-transmitted helminth infections. 2020. Available from https://www.who.int/news-room/ fact-sheets/detail/soil-transmitted-helminthinfections

6. Worms in India: The scale up and success of a world-leading deworming programme. 2019. Available from https://ciff.org/news/worms-indiascale-and-success-world-leading-dew ormingprogramme/

7. Saboya MI, et al. Update on the mapping of Prevalence and intensity of infection for soil transmitted helminth infections in latin America nd the Caribbean: A call for action. PlosNegiTrop Dis. 
2013:7:2419

8. M U Anah ${ }^{1,} \mathrm{O}$ E Ikpeme, I S Etuk, K E Yong, I Ibanga, B E Asuquo. Worm Infestation and Anaemia Among Pre-School Children of Peasant Farmers in Calabar, Nigeria. Niger $J$ Clin Pract.2008 Sep;11(3):220-4.https://pubmed.ncbi. nlm.nih.gov/19140358/

9. Shakya B, Shrestha S, Madhikarmi NL, Adhikari R. Intestinal parasitic infection among school children. Nepal Health Research Council. 2012; 10(20): 20-3.

10. Vinod Kumar CS, Anand Kumar H., Sunita V., Indu Kapur. Neonatal of microbiology,K.B.N. Instititue of Medical Sciences, Gulbarga 585 104, Karnataka, India. Indian Pediatrics 2003;40:70-72. https://www.indianpediatrics.net/jan2003/jan-7072.htm

11. Mrs. Sadhna Shinde1; Dr. Suresh Ray 2; Mrs. Karpagavalli N3. Asian Academic Research Journal of Multidisciplinary. volume 2 issue 5 (october 2015) ISSN: $2319-2801$

12. Suganya V1, Jaimy Scaria 2, Dr. Indira S3, B Kavitha4, Ramya K5, Revathi D6, Naveen Kumar MR7. International Journal of Academic Research and Development. Volume 3; Issue 2; March 2018; Page No. 1075-1078

13. Mr. Madan Mohan Gupta1, Mrs. Sameeksha Bhardwaj 2, Mr. Bharat Bansal3. JNPE, June 2017, Vol. 3, Issue 2, pp. $28-32$

14. Sharma Ankita $^{1}$, Kaur Sandeep ${ }^{2}$, Chaudhary Anurag $^{3}$. International Journal of Nursing Care. Year : 2017, Volume : 5, Issue : 1
15. M. Hemamalini ${ }^{1}$ S. Divya ${ }^{2}$. Community and Public Health Nursing- F CPHN 2017; 2 (1) : 13-16;

16. Mrs. Rimple Sharma, Ms. Poonam Sharma and Ms. Harpreet Kaur. International Journal of Current Research, (IJCR). https://www.journalcra.com/ article/comparative-study-assess-knowledgeregarding worm-infestation-children-amongurban-and-rural

17. Y, jebasubitha.a study to assess the effectiveness of structured teaching programme on knowledge regarding prevention of worm infestation among mothers of under five children in selected hospital, Bangalore. http://52.172.27.147:8080/jspui/ handle/123456789/7926

18. Jagadeesan M, Mariraj I, Prasanna Karthik S, Kannan R, Nivaas M, Lohitya J, Raghul U, \& Farah Kamaludeen. (2019). International Journal of Research in Pharmaceutical Sciences, 10(3), 18181820 .

19. Mareeswaran $\mathrm{N}$ et al. Int J Community Med Public Health. 2018 Jun;5(6):2585-2589

20. V. Priya 1 and P. Abirami 2 .International Journal of Pharmacy and Biological Sciences.IJPBS Volume 6 | Issue 2 | Apr-Jun | 2016 | 23-28

21. Amar Tripura, Taranga Reang, Kaushik Tripura, Arundhuti Roy. Journal of Evolution of Medical and Dental Sciences 2013; Vol 2, Issue 47, November 25; Page: 9081-9087, DOI: 10.14260/jemds/1575 